\title{
Development of a Planetary Protection Laboratory for Mars Missions
}

\author{
By Takashi Ozawa, ${ }^{1)}$ Kazuhisa FuJITA, ${ }^{1)}$ Yukihiko SHIMIZu, ${ }^{2)}$ Akihiko YAMAGISHI ${ }^{3)}$ and Takehiko SATOH ${ }^{2)}$ \\ ${ }^{1)}$ Research and Development Directorate, JAXA, Chofu, Japan \\ ${ }^{2)}$ Institute of Space and Aeronautical Science, JAXA, Sagamihara, Japan \\ ${ }^{3}$ Tokyo University of Pharmacy and Life Sciences, Hachioji, Japan
}

(Received July 13th, 2015)

\begin{abstract}
At Japan Aerospace Exploration Agency (JAXA), several types of Mars missions have been lately proposed and studied. In order to improve the feasibility of the Mars missions, it is crucial to develop a planetary protection (PP) facility so that we prevent the celestial body from biological contamination. The PP requirements need to be specified for each planetary mission in accordance with the mission objective. Since the COSPAR PP policy categorizes Mars landing missions into Category 4, a PP facility for Category 4 has been studied and planned at JAXA. In addition, a pilot model of a bioburden sample laboratory has been developed, and essential procedures, such as bioburden assay and dry heat sterilization, have been studied in this work.
\end{abstract}

Key Words: Mars, Planetary Protection, Bioburden

\section{Nomenclature}

$\begin{array}{lll}A & : & \text { area } \\ n & : & \text { average number of colony } \\ V & : & \text { volume }\end{array}$

Subscripts

$\begin{array}{lll}\mathrm{C} & \text { : } & \text { count } \\ \mathrm{L} & : & \text { liquid } \\ \mathrm{P} & : & \text { plate } \\ \mathrm{S} & : & \text { sample }\end{array}$

\section{Introduction}

At Japan Aerospace Exploration Agency (JAXA), several types of Mars missions, ${ }^{1)}$ such as rover, lander, orbiter, Mars airplane, sample return, ${ }^{2)}$ etc. have been lately studied. The planetary protection (PP) requirements need to be specified for each planetary mission in accordance with the mission objective so that we prevent the celestial body from biological contamination. The Committee On Space Research (COSPAR) basically categorizes space missions into 5 categories $^{3)}$ according to the target body potential of extraterrestrial organisms and the type of encounter. As the potential of the target body about life or prebiotic chemical evolution becomes higher, a higher operating restriction will be imposed. The categories are summarized in table 1, and the COSPAR planetary protection policy categorizes Mars landing missions into Category 4. ${ }^{4}$ For Category 3 or higher, bioburden control is necessary. However, JAXA currently does not have bioburden-controlled environments that meet requirements of COSPAR Planetary Protection Policy. Therefore, it is crucial to develop a planetary protection facility so as to improve the feasibility of Mars missions at JAXA.

One of the Mars landing mission objectives at JAXA is to investigate extant Martian life,$^{5)}$ and therefore, we expect the landing system to access Martian special regions. There are three subcategories for Mars landing missions, and missions that investigate Martian special regions are categorized as Category $4 \mathrm{c}$. For the Category $4 \mathrm{c}$, the highest requirements regarding outbound planetary missions are specified, such as "The entire landing system is restricted to a surface biological burden level not exceeding 30 spores." In this work, we discuss a planetary protection plan for Category $4 \mathrm{c}$ at JAXA, and demonstrate bioburden procedures, such as bioburden assays and dry heat sterilization.

Table 1. Classification of COSPAR planetary protection.

\begin{tabular}{|c|c|c|}
\hline Cat. & Definition & Targeted Planets \\
\hline 1 & $\begin{array}{l}\text { All types of missions to a target body where there is } \\
\text { no scientific interest relative to the process of } \\
\text { chemical evolution and the origins of life }\end{array}$ & $\begin{array}{l}\text { S-type asteroids, } \\
\text { Io, Mercury }\end{array}$ \\
\hline 2 & $\begin{array}{l}\text { All types of missions to a target body where there is } \\
\text { significant scientific interest relative to the process } \\
\text { of chemical evolution and the origins of life, but } \\
\text { there is only a remote chance that contamination by } \\
\text { a spacecraft can compromise future investigations. }\end{array}$ & $\begin{array}{l}\text { P, D, C-type ast- } \\
\text { eroids, Moon, } \\
\text { Venus, Jupiter, } \\
\text { Saturn, Uranus, } \\
\text { Neptune, Pluto, } \\
\text { Comets, etc }\end{array}$ \\
\hline & $\begin{array}{l}\text { Fly-by and orbital missions to a target body where } \\
\text { there is significant scientific interest relative to the } \\
\text { process of chemical evolution and the origins of life } \\
\text { and there is a significant chance that contamination } \\
\text { by a spacecraft can compromise future } \\
\text { investigations. }\end{array}$ & $\begin{array}{l}\text { Mars, Europa, } \\
\text { Enceladus }\end{array}$ \\
\hline & $\begin{array}{l}\text { Surface missions to a target body where there is } \\
\text { significant scientific interest relative to the process } \\
\text { of chemical evolution and the origins of life and } \\
\text { there is a significant chance that contamination by a } \\
\text { spacecraft can compromise future investigations. }\end{array}$ & $\begin{array}{l}\text { Mars, Europa, } \\
\text { Enceladus }\end{array}$ \\
\hline & $\begin{array}{l}\text { All Earth-return missions. } \\
\text { (A) Unrestricted: For Solar system bodies deemed } \\
\text { by scientific opinion to have no indigenous life } \\
\text { forms } \\
\text { (B) Restricted: For all other Category V missions. }\end{array}$ & $\begin{array}{l}\text { (A) Unrestricted } \\
\text { (Return from } \\
\text { Cat. 1 and 2) } \\
\text { (B) Restricted } \\
\text { (Return from } \\
\text { Mars, Europa, } \\
\text { etc.) }\end{array}$ \\
\hline
\end{tabular}




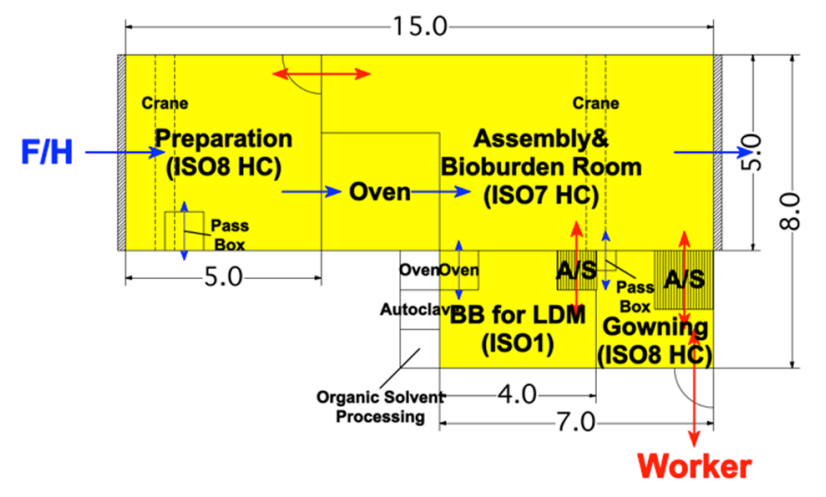

Fig. 1. Planetary protection facility layout for Category 4.

\section{Planetary Protection Plan}

\subsection{Planetary protection facility plan}

In order to meet requirements of COSPAR Planetary Protection Policy Category 4c, a planetary protection facility has been designed at JAXA and shown in Fig. 1. The facility consists of four sterilized and bioburden controlled clean rooms (CRs): a gowning room, a preparation room, an assembly and bioburden assay room, and a bioburden assay room for life detection module (LDM). The facility also requires a sample analysis laboratory room and a $\mathrm{CR}$ administrative room as well as accessibility to environment test rooms. Bioburden controlled environments are designed to be equivalent to airborne particulate cleanliness class ISO8 highly controlled (HC) or better, and all flight hardware basically need to undergo dry heat sterilization prior to entering the bioburden assay room (ISO7 HC). ${ }^{6}$ ) Thus, each bioburden room is equipped with its own clean ovens.

\subsection{Bioburden laboratory}

In order to control the bioburden level of instruments and assemblies for the mission as well as the facility environment, essential procedures of bioburden assays and sterilization need to be established and involved personnel should be well-trained. Thus, in this work we have designed a bioburden analysis laboratory as shown in Fig. 2, and developed a pilot model to study bioburden control techniques and sterilization procedures (see Fig. 3). The laboratory is equipped with a dry desiccator, a refrigerator, an incubator, a water bath, a clean bench, a dry heat sterilizer, an autoclave, etc. In this laboratory, we first carry out falling bacteria assay for the evaluation of laboratory environments. Second, we conduct swab assay or wipe assay in accordance with the sample size for bioburden control, and evaluate the contamination level using petrifilm plates and several types of agar plates. Third, we utilize the Dry Heat Microbial Reduction (DHMR) method as the basic sterilization process, and establish sterilization procedures for flight instruments and assemblies.

\subsection{Bioburden assay procedure}

To meet planetary protection requirements, both bioburden (quantity of viable microorganisms) and biodiversity (identification of type of microorganism) should be investigated by specified assays. Swab and wipe assays should be carried out for flight hardware surfaces with an area of maximum $25 \mathrm{~cm}^{2}$ and with an area of maximum $1 \mathrm{~m}^{2}$,

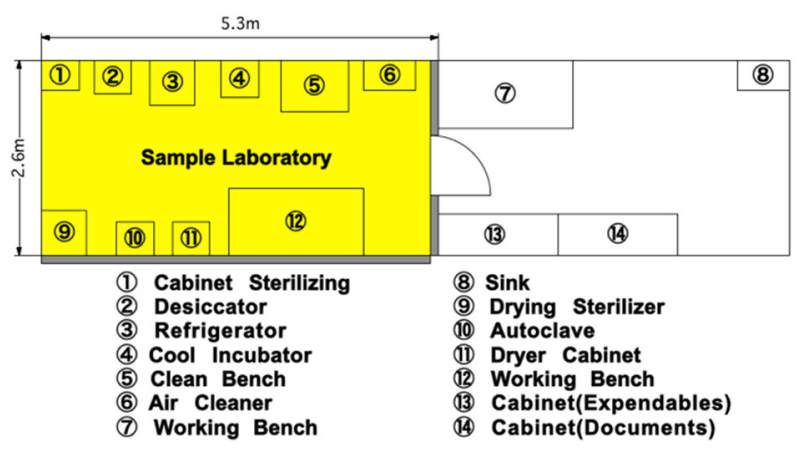

Fig. 2. Design of bioburden laboratory at JAXA.

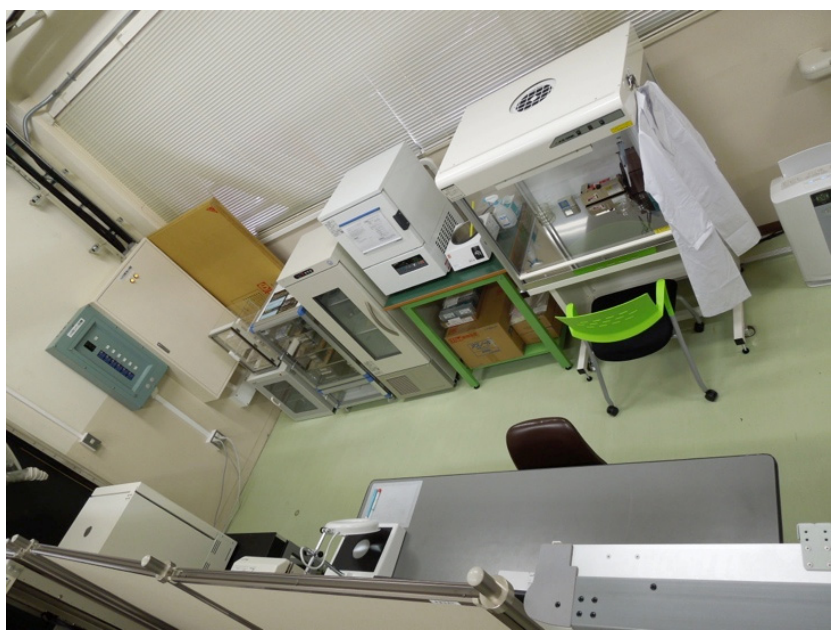

Fig. 3. Bioburden pilot laboratory at JAXA.

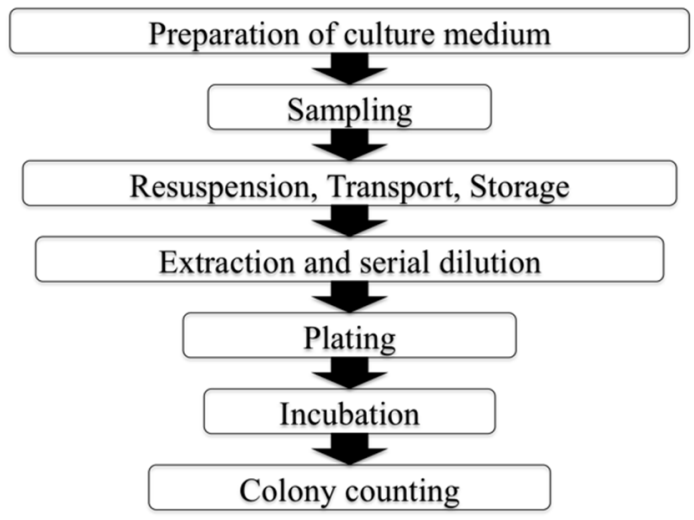

Fig. 4. Bioburden assay procedure.

respectively, and bioburden should be determined with assays for quantification of aerobic mesophilic bacteria.7) On the other hand, biodiversity should be determined with assays for determination of the type of microorganism. In this study, we demonstrate swab bioburden assays. In Fig. 4, bioburden assay procedure is summarized. 
(1) Preparation of culture medium

In this study, we use petrifilm (aerobic count plates), standard agar nutrient medium, and desoxycholate agar medium as culture medium. Agar culture medium should be sterilized prior to assays by autoclaves, and so forth. For swab assay, we prepare a sufficient number of sterile swabs and test tubes with sterile water for all swab samples.

\section{(2) Sampling}

We hold the swab so that the handle makes about a $30^{\circ}$ angle with the surface to be sampled. While moving the swab in one direction, we rotate the head of the swab slowly and thoroughly over a measured surface area. Then, we change the linear direction of the swabbing motion $90^{\circ}$ and again swab the surface thoroughly. We complete a third coverage of the surface by again changing the direction of the swabbing motion by $135^{\circ}$.

(3) Resuspension, transport, and storage

We return the swab head to a tube containing $10 \mathrm{ml}$ sterile water, transport samples to the laboratory, store at $(4-8){ }^{\circ} \mathrm{C}$, and process within 24 hours.

(4) Extraction and serial dilution

We vortex the tube for 5 seconds, and dilute the sample if necessary.

(5) Plating

We aseptically pipette $1 \mathrm{ml}$ aliquots of the swab extraction suspension onto the surface of culture medium. We use $2 \mathrm{ml}$ in total.

(6) Incubation

Plates should be inverted and incubated at $(32 \pm 1){ }^{\circ} \mathrm{C}$.

(7) Colony Counting

We examine the sample plates at 24 and 48 hours. If colonies visible by eyes are observed, count and record data. Then, we examine and record final colony counts at 72 hours.

\subsection{Preparation and sterilization}

Prior to the bioburden assays, instruments and culture medium should be sterilized by a suitable sterilization method. In the lab., we utilize five sterilization methods: autoclave sterilization, hot water bath sterilization, flame sterilization, ultraviolet sterilization, alcoholic sterilization (see Fig. 5). For instance, standard agar medium should be sterilized by an autoclave with $121^{\circ} \mathrm{C}$ for 15 minutes.

Sterilization is a killing process of all microorganisms. Sterilization processes are qualified in terms of probability to find one reference microorganism after their application, using the common and most resistant organism with respect to the sterilization method, named the Sterility Assurance Level (SAL). SAL $10^{-6}$ is generally used to determine sterilization parameters. The DHMR method ${ }^{8)}$ has been widely used and validated as the basic sterilization process for bioburden control, and thus, we demonstrate the DHMR procedure in this work. The DHMR minimum temperature is $110{ }^{\circ} \mathrm{C}$, and the maximum humidity level is $1.2 \mathrm{~g} / \mathrm{m}^{3}$ water. The qualified DHMR parameters for SAL $10^{-6}$ are $125{ }^{\circ} \mathrm{C} / 48 \mathrm{~h}$ or $135{ }^{\circ} \mathrm{C} / 12 \mathrm{~h} .{ }^{9)}$

In Fig. 6, we present a flow diagram for sterilization and bioburden procedure. As shown in the figure, we carry out a pre-test on the same sample and we compare the bioburden between two cases with and without sterilization procedure. From the comparison, we determine the suitability of the sterilization method for the sample component. Sterilization

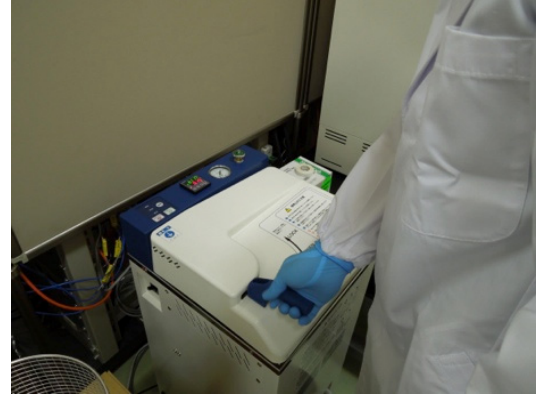

(A) Autoclave

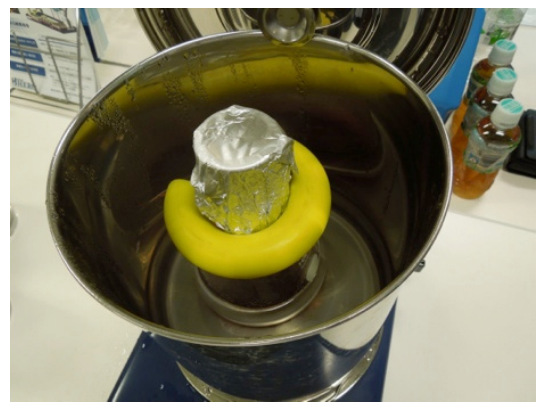

(B) Hot water bath sterilization

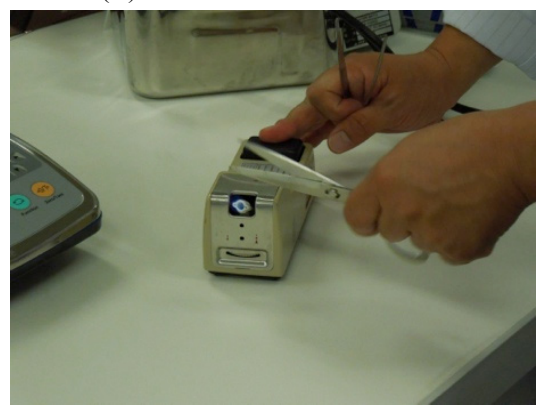

(C) Flame sterilization

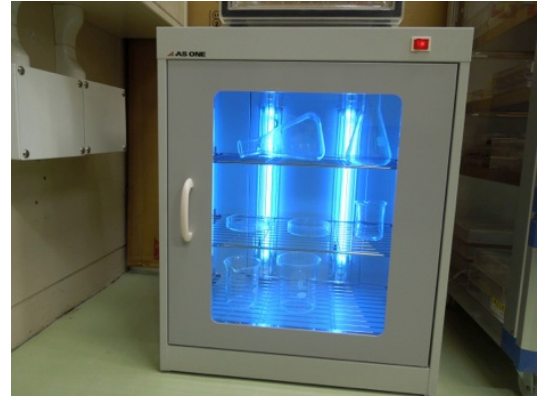

(D) Ultraviolet sterilization

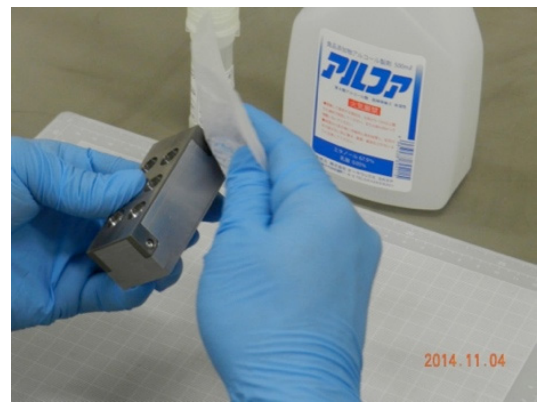

(E) Alcoholic Sterilization

Fig. 5. Sterilization of instruments and nutrient medium.

processes should be applied to all flight hardware, and the proper sterilization method and parameters should be selected for each component. 


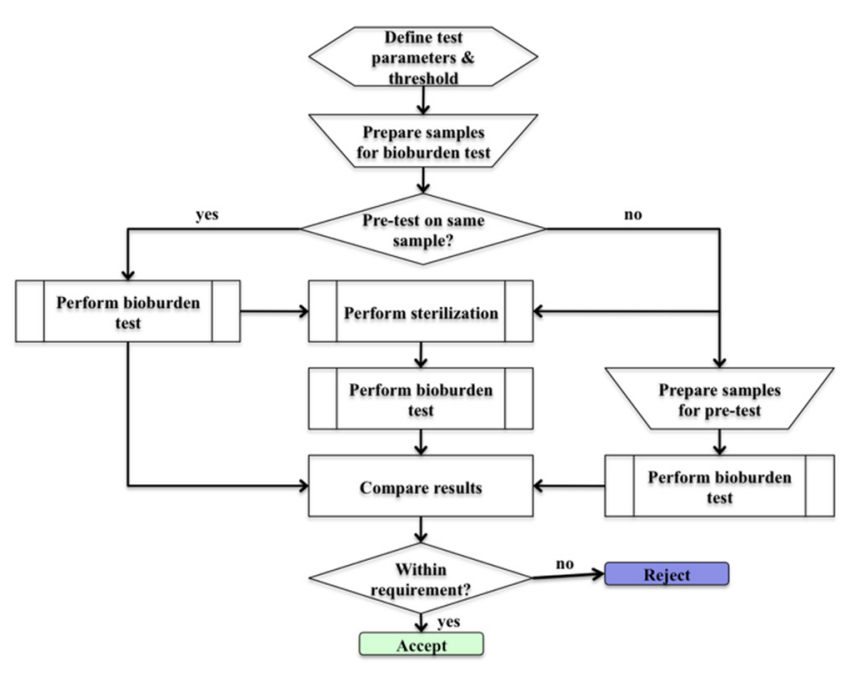

Fig. 6. Flow diagram for sterilization and bioburden procedure.

\section{Results and Discussions}

\subsection{Falling bacteria assay}

First, we have carried out falling bacteria assay in the bioburden pilot laboratory to evaluate the cleanliness of the environment. For the falling bacteria assay, we have utilized three types of plates: petrifilm (aerobic count plates), standard agar nutrient medium, and desoxycholate agar medium (see Fig. 7). While the petrifilm and standard agar nutrient medium are used for common aerobic bacteria, the desoxycholate agar is used as a differential medium for the direct count of coliforms. The general procedure using petrifilm for the falling bacteria assay is as follows.

(1) Prepare four petrifilms (aerobic count plates) for 0, 5, 10, and 15 minutes sampling.

(2) Lift a top film, and hold pipette perpendicular to the plate and dispense $1 \mathrm{ml}$ aliquots of $9 \mathrm{ml}$ sterile water onto the center of the bottom film aseptically.

(3) Release the top film down onto the bottom.

(4) Distribute the water evenly using a special spreader for 20- $\mathrm{cm}^{2}$ area.

(5) Remove the spreader and leave plate undisturbed for 30 minutes to permit solidification of the gel.

(6) Place three petrifilms on an $80 \mathrm{~cm}$ height flat surface board at the sampling location, and lift the top film.

(7) Start falling bacteria sampling using both of the top and bottom films for 5, 10, and 15 minutes (see Fig. 7).

(8) After the sampling, incubate plates at $35 \pm 1.0^{\circ} \mathrm{C}$ for $48 \pm$ 3 hours.

(9) Count all red dots as colonies on a standard colony counter.

The general procedure using agar media for the falling bacteria assay is as follows.

(1) After sterilizing agar media, pour approximately $15 \mathrm{ml}$ agar media into each sterilized petri plate aseptically.

(2) Swirl the hot media to mix, and wait for 30 minutes for cooling aseptically.

(3) Place agar plates on an $80 \mathrm{~cm}$ height flat surface board at the sampling location.

(4) Start falling bacteria sampling for 5, 10, and 15 minutes

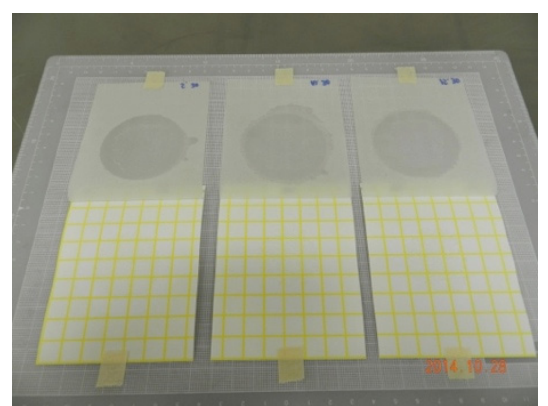

(1) Petrifilm

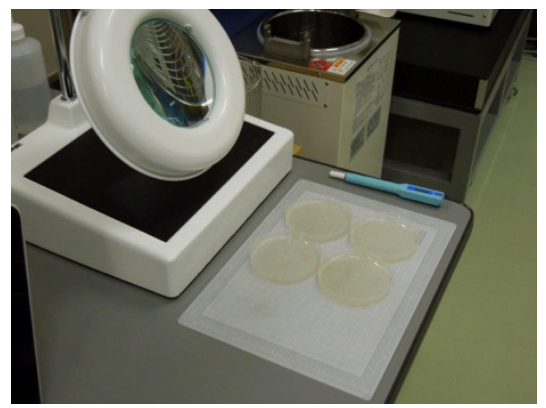

(2) Agar nutrient medium (standard)

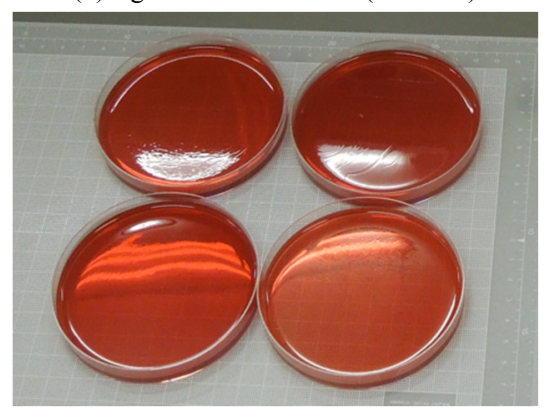

(3) Desoxycholate agar medium

Fig. 7. Falling bacteria sampling with petrifilm and agar medium. (see Fig. 7).

(5) After the sampling, incubate plates at $35 \pm 1.0^{\circ} \mathrm{C}$ for $48 \pm$ 3 hours.

(6) Count all colonies on a standard colony counter.

The results of falling bacteria assay are summarized in Table 2. It can be seen in the figure, basically colonies were rarely found for all three cases. The tests were carried out in the following environment.

(1) The test space was approximately $40 \mathrm{~m}^{-3}$.

(2) Number of resident persons was one.

(3) While an air purifier was in operation, an air conditioner was off.

Table 2. Comparison of falling bacteria assay.

\begin{tabular}{|c|c|c|c|c|}
\hline $\begin{array}{c}\text { Culture } \\
\text { medium }\end{array}$ & Sample & $\begin{array}{c}\text { Time } \\
{[\mathrm{min}]}\end{array}$ & $\begin{array}{c}\text { Number of } \\
\text { colony }\end{array}$ & $\begin{array}{c}\text { Viable count } \\
{\left[\mathrm{cm}^{-2}\right]}\end{array}$ \\
\hline Petrifilm & Falling bacteria & 0 & 0 & 0.0 \\
\hline Petrifilm & Falling bacteria & 5 & 1 & 0.03 \\
\hline Petrifilm & Falling bacteria & 10 & 0 & 0.0 \\
\hline Petrifilm & Falling bacteria & 15 & 0 & 0.0 \\
\hline Agar & Falling bacteria & 0 & 0 & 0.0 \\
\hline Agar & Falling bacteria & 5 & 0 & 0.0 \\
\hline Agar & Falling bacteria & 10 & 0 & 0.0 \\
\hline Agar & Falling bacteria & 15 & 2 & 0.03 \\
\hline Agar & palm & NA & 62 & 1.03 \\
\hline Desoxycholate & Falling bacteria & 0 & 0 & 0.0 \\
\hline Desoxycholate & Falling bacteria & 5 & 0 & 0.0 \\
\hline Desoxycholate & Falling bacteria & 10 & 0 & 0.0 \\
\hline Desoxycholate & Falling bacteria & 15 & 0 & 0.0 \\
\hline
\end{tabular}




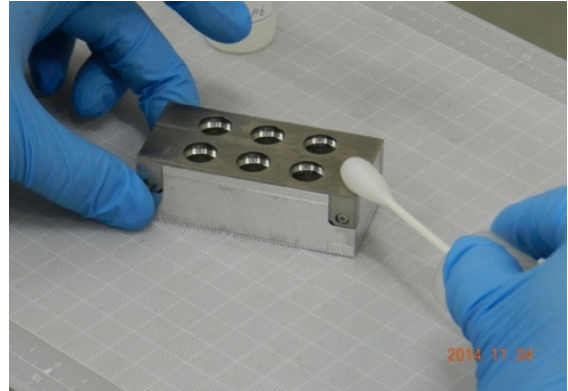

(1) Swab sampling

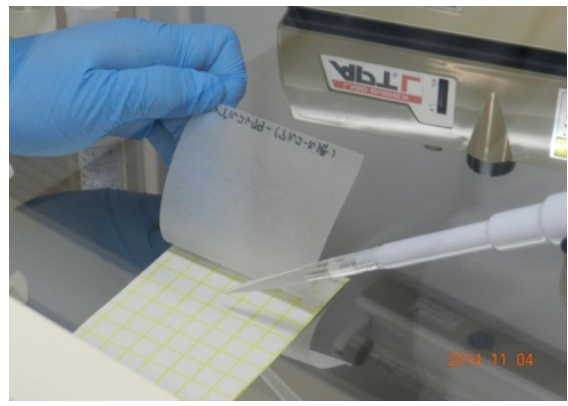

(2) Plating

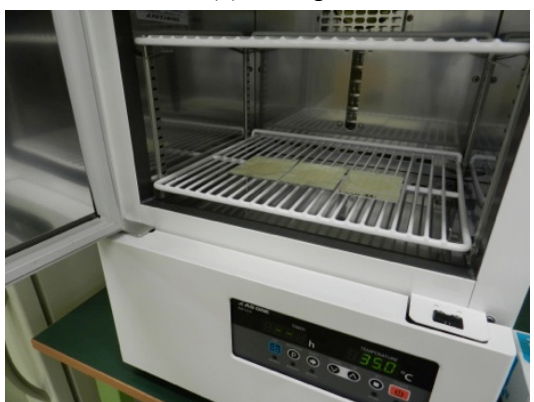

(3) Incubating

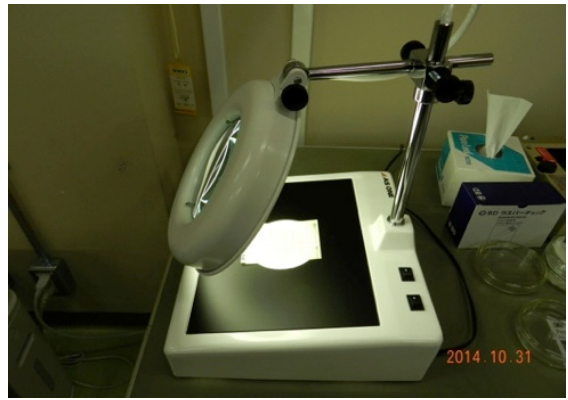

(4) Colony Counting

Fig. 8. Procedure of bioburden swab assay.

In order to validate the quality of the agar media, a direct palm assay has also been conducted and its result is compared in the table. Evidently, the contamination potential due to human handling is significantly higher than the falling bacteria in the laboratory. The contamination level of falling bacteria is approximately $10^{6}$ colony forming unit (CFU)/ $\mathrm{m}^{2}$-week, which is comparable to the ISO class 8 (bio-clean room class $100,000)$ reference value of $323,000 \mathrm{CFU} / \mathrm{m}^{2}$-week. Namely, the cleanliness of the bioburden laboratory is between ISO class 8 and 9, where the condition is relatively clean room air.

\subsection{Swab assay demonstration}

We have carried out the swab assay demonstration for the surface of a sample collector bread board model (BBM), which has been developed for the Mars Aero-flyby Sample

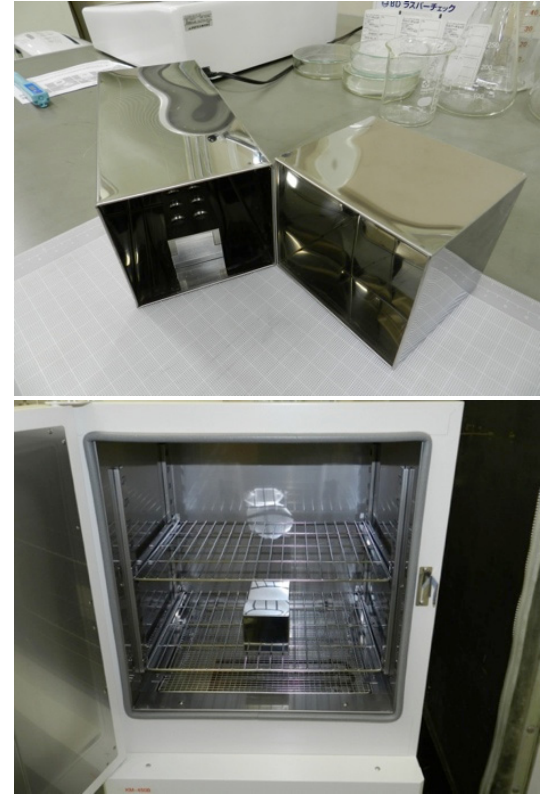

Fig. 9. Dry heat microbial reduction.

Collection (MASC) mission. The detail of the test model is as follows.

(1) The size of sample collector BBM is W30 $\times$ D $66 \times \mathrm{H} 24 \mathrm{~mm}$

(2) The test surface area is approximately $86 \mathrm{~cm}^{2}$

(3) The materials are titanium and aluminum.

(4) This has been handled by hands without any gloves.

The general swab assay procedure is explained in subsection. 2.3. For this demonstration, petrifilms (aerobic count plates) have been used as shown in Fig. 8. After the sampling with a sterilized swab, we return the swab to a tube containing $10 \mathrm{ml}$ sterile water, and without any dilution, we aseptically pipette $1 \mathrm{ml}$ aliquots of the swab extraction suspension onto the petrifilm surface. Then, the plates have been incubated at $35( \pm 1){ }^{\circ} \mathrm{C}$, and the colonies have been counted at 24,48 , and 72 hours by using a colony counter pen on a stand. After 48-hour incubation, the number of colony was $31 \mathrm{CFU}$ per $20 \mathrm{~cm}^{2}$ since this sample had been handled without any bioburden control. The average number of colonies on the surface can be estimated by the following equation as

$$
n=n_{C} A_{P} V_{L} / A_{S} .
$$

As a result, the average number of colonies on the surface is approximately $0.36 \mathrm{CFU} / \mathrm{cm}^{2}$ without any sterilization processes.

\subsection{Sterilization demonstration}

In order to demonstrate sterilization procedures, we have compared the following three cases:

(A) Without any sterilization

(B) Alcoholic sterilization for the surface

(C) Dry Heat Microbial Reduction (DHMR) method with $135^{\circ} \mathrm{C} / 12 \mathrm{~h}$ (see Fig. 9)

After 48-hour incubation, the number of colonies has been

Table 3. Comparison of swab assay for a sample collector.

\begin{tabular}{|c|c|c|c|}
\hline Case & Sterilization & Number of colony & Viable count $\left[\mathrm{cm}^{-2}\right]$ \\
\hline $\mathrm{a}$ & - & 31 & 3.6 \\
\hline $\mathrm{b}$ & Alcohol & 0 & 0.0 \\
\hline $\mathrm{c}$ & DHMR & 0 & 0.0 \\
\hline
\end{tabular}




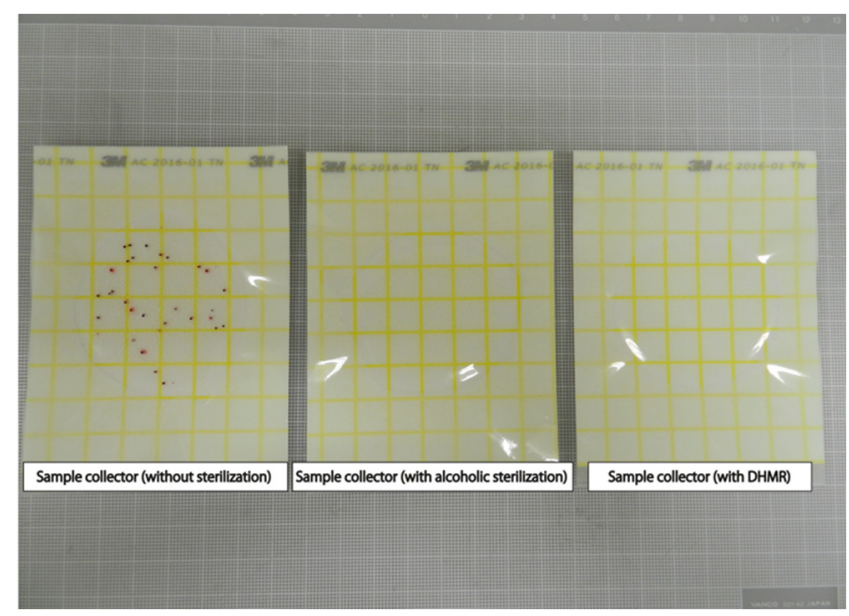

Fig. 10. Comparison of colonies among three swab assays: (a) without sterilization, (b) with alcoholic sterilization, (c) with DHMR.

counted, and the results are summarized in Table 3 (see also Fig. 10). Without any bioburden control, the averaged CFU on the tested surface is approximately $3.6 \mathrm{CFU} / \mathrm{cm}^{2}$, which is significantly higher than the requirement limit of $0.03 \mathrm{CFU} / \mathrm{m}^{2}$ for Category 4c. With alcoholic sterilization, colonies were not detected since this method is effective on the smooth metallic surfaces. Similarly, with DHMR, colonies were not detected, and thus, the DHMR sterilization effect has been validated.

\section{Conclusions}

We have studied planetary protection and developed a PP plan for Category 4 in order to improve the feasibility of Mars landing missions. In addition, a pilot model of a bioburden sample laboratory has been established at JAXA, and essential procedures, such as bioburden assay and dry heat sterilization, have been demonstrated in this work. First, falling bacteria assays using three types of culture media have been carried out to assess the environment of the bioburden laboratory. Second, the validity of the DHMR method has been demonstrated by conducting swab assays for a Martian dust sample collector BBM.

\section{Acknowledgments}

We would like to acknowledge Dr. Kminek of ESA and Dr. Margheritis of Thales Alenia Space Italy for the advice and assistance of the planetary protection plan.

\section{References}

1) Fujita, K., et al.: Japan's Mars Rover Mission - System Design \& Development Status, ISTS Paper 2015-k-37, 30th International Symposium on Space Technology and Science, July 4-10, 2015, Kobe-Hyogo, Japan.

2) Fujita, K., et al.: Conceptual Study and Key Technology Development for Mars Aeroflyby Sample Collection, Acta Astronautica, 93 (2014), pp. 84-93.

3) COSPAR Planetary Protection Policy, latest version.

4) Kminek, G./TEC-QI: ESA Planetary Protection Requirements, ESSB-ST-U-001, European Cooperation for Space Standardization, 2012.

5) Yamagishi, A., et al.: Life Detection Microscope - in-situ imaging of living cells on Mars surface -, 40th COSPAR Scientific Assembly, Moscow, Russia, Aug. 2-10, 2014.

6) ESA Requirements and Standards Division: Space Product Assurance, Bioburden Control of Cleanrooms, ECSS-Q-ST-70-58C, European Cooperation for Space Standardization, 2008.

7) ESA Requirements and Standards Division: Space Product Assurance, Microbial Examination of Flight Hardware and Cleanrooms, ECSS-Q-ST-70-55C, European Cooperation for Space Standardization, 2008.

8) ESA Requirements and Standards Division: Space Product Assurance, Dry Heat Bioburden Reduction for Flight Hardware, ECSS-Q-ST-70-57C, European Cooperation for Space Standardization, 2013.

9) ESA Requirements and Standards Division: Space Product Assurance, Materials and Hardware Compatibility Tests for Sterilization Processes, ECSS-Q-ST-70-53C, European Cooperation for Space Standardization, 2008.

10) Ozawa,T., Suzuki,T., Kurosawa, K., Hatakeyama, Y., Fujita, K.: Investigation of New Martian Dust Sample Capture System, Transactions of the Japan Society for Aeronautical and Space Sciences, Aerospace Technology Japan, 12 (2014), pp. Pr7-Pr12. 